\title{
Acceleration of Vaporization, Atomization, and Ionization Efficiencies in Inductively Coupled Plasma by Merging Laser- Ablated Particles with Hydrochloric Acid Gas
}

\author{
Takashi NaKazawa, Saori Izumo, and Naoki Furuta ${ }^{\dagger}$ \\ Faculty of Science and Engineering, Department of Applied Chemistry, Chuo University, 1-13-27 Kasuga, \\ Bunkyo, Tokyo 112-8551, Japan
}

\begin{abstract}
To accelerate the vaporization, atomization, and ionization efficiencies in laser ablation inductively coupled plasma mass spectrometry, we merged $\mathrm{HCl}$ gas with laser-ablated particles before introduction into the plasma, to convert their surface constituents from oxides to lower-melting chlorides. When particles were merged with $\mathrm{HCl}$ gas generated from a $\mathrm{HCl}$ solution at $200^{\circ} \mathrm{C}$, the measured concentrations of elements in the particles were $135 \%$ higher on average than the concentrations in particles merged with ultrapure water vapor. Particle corrosion and surface roughness were observed by scanning electron microscopy, and oxide conversion to chlorides was confirmed by X-ray photoelectron spectroscopy. Under the optimum conditions, the recoveries of measured elements improved by $23 \%$ on average, and the recoveries of elements with high-melting oxides $(\mathrm{Sr}, \mathrm{Zr}$, and $\mathrm{Th}$ ) improved by as much as $36 \%$. These results indicate that vaporization, atomization, and ionization in the ICP improved when $\mathrm{HCl}$ gas was merged with the ablated particles.
\end{abstract}

Keywords Laser ablation, NIST glass standard, $\mathrm{HCl}$ gas, infrared lamp heating device, conversion from oxides to chlorides, melting points, boiling points, ICP-MS, SEM, XPS

(Received May 24, 2016; Accepted August 1, 2016; Published December 10, 2016)

\section{Introduction}

Laser ablation inductively coupled plasma mass spectrometry (LA-ICPMS) permits a local, rapid analysis of solid samples. However, incomplete vaporization of ablated particles in the ICP leads to inefficient vaporization, atomization, and ionization. ${ }^{1}$ For example, when gold nanoparticles are measured after direct introduction into the ICP, a non-linear calibration curve is observed, owing to incomplete vaporization, and the extent of vaporization decreases with increasing particle diameter. $^{2}$

We have been monitoring airborne particulate matter (APM) in the Tokyo area since 1995..$^{3-5}$ Recently, Nishiguchi et al. realized real-time monitoring by a direct introduction of APM into an ICP by means of a gas exchange device (GED), which permits the exchange of air for argon molecules without the loss of APM. ${ }^{6,7}$ We have reported the use of a GED to determine $\mathrm{Pb}$ in a single particle of APM. ${ }^{8}$ However, during real-time monitoring, we found that accurate results could not be obtained for elements that have oxides with high melting points. ${ }^{9}$ Elements in particles introduced into the ICP are measured after melting, vaporization, atomization, and ionization, and the inaccuracies during real-time monitoring have been attributed to incomplete vaporization, atomization, and ionization in the initial radiation zone of the ICP. Günther and co-workers reported that when glass is analyzed by LA-ICPMS, the signal intensities of elements with high-melting oxides are lower than those of elements with low-melting oxides. ${ }^{10,11}$ Recently, we reported that ablated particles lager than $220 \mathrm{~nm}$ could not be decomposed in the ICP when glass is analyzed by LA-ICPMS, and that caused major elemental fractionation. ${ }^{12,13}$

In this study, we took advantage of the fact that the melting points of the chlorides of elements are lower than those of the corresponding oxides, and we used hydrochloric acid $(\mathrm{HCl})$ gas to convert the oxide constituents of ablated particles to the corresponding chlorides. Specifically, NIST SRM 610, a glass standard, was ablated, and ablated particles with diameters of less than $1 \mu \mathrm{m}$ were selected by passage through a cascade impactor. Between the impactor and the ICP, we placed an infrared lamp heating device in which $\mathrm{HCl}$ gas was merged with the ablated particles, with the goal of improving the vaporization, atomization, and ionization efficiencies of particles introduced into the ICP. The morphology and chemical constituents of the particles after reacting with the $\mathrm{HCl}$ gas were investigated by means of scanning electron microscopy (SEM) and X-ray photoelectron spectroscopy (XPS), respectively.

In the ICPMS analyses, ions produced from particles in the ICP were detected by MS, whereas in the SEM and XPS analyses, the particles were measured after being collected on carbon tape. The melting points and boiling points of the elements and their oxides were important parameters that affected the experimental results obtained by ICPMS, SEM, and XPS.

† To whom correspondence should be addressed.

E-mail: nfuruta@chem.chuo-u.ac.jp 


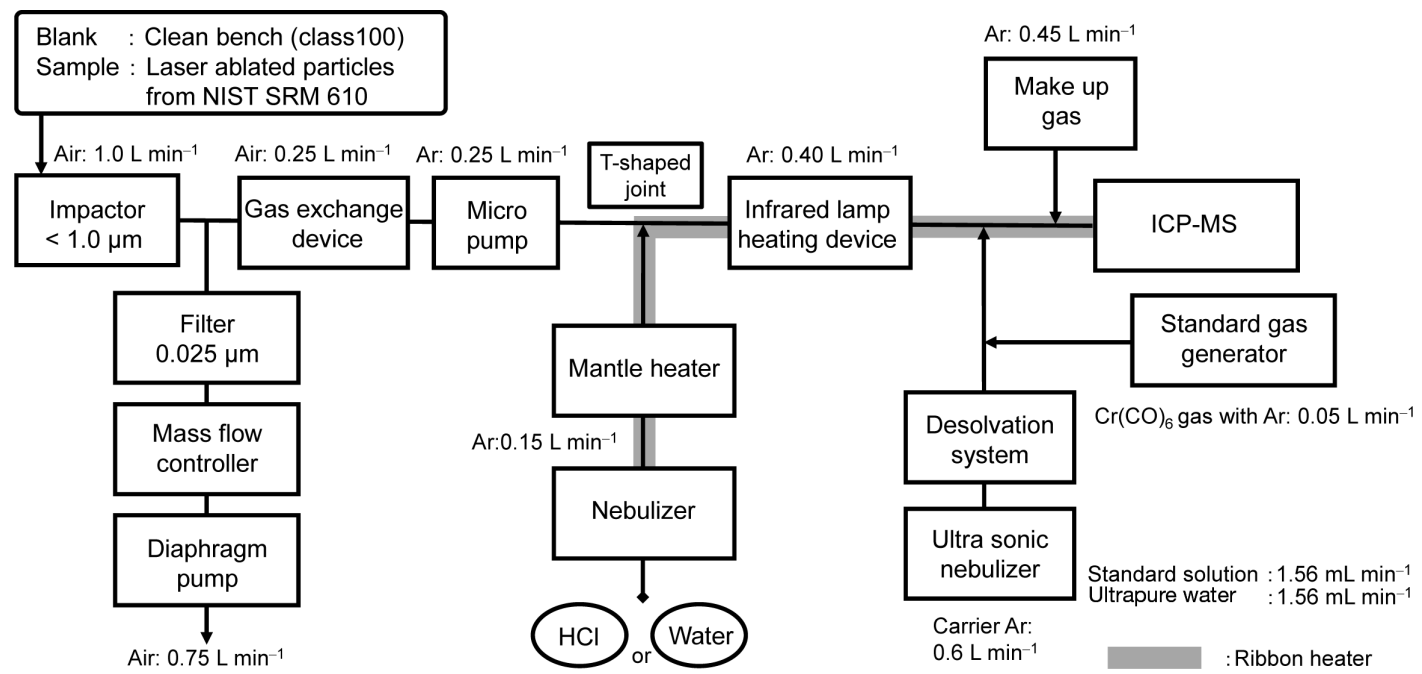

Fig. 1 Schematic diagram of experimental setup.

\section{Experimental}

\section{Instrumentation}

A schematic diagram of the experimental setup is shown in Fig. 1. NIST SRM 610, a glass standard, was ablated by means of a LA system (UP213, ESI, Portland, OR, USA) operated in the line-scan mode, and ablated particles in air were collected. An air blank was collected from a class 100 clean bench equipped with HEPA filters. The air blank or ablated particles were introduced into a cascade impactor (inline type with NL-11A $(<1.0 \mu \mathrm{m})$, Tokyo Dylec Co., Tokyo, Japan) at a flow rate of $1.0 \mathrm{~L} \mathrm{~min}{ }^{-1}$; only ablated particles with diameters of $<1.0 \mu \mathrm{m}$ were measured.

A portion of the sample was introduced at a flow rate of $0.25 \mathrm{~L} \mathrm{~min}^{-1}$ into a GED (J-Science Lab Co., Kyoto, Japan), which exchanged air for Ar molecules. GED consists of an inner porous glass tube and two outside glass tubes. Ar gas is flowing in the outside gas tubes with a high speed flow rate. There is a pressure difference between inside and outside of the porous glass. Therefore, when a sample is passing through the inner porous glass tube, gas molecules are exchanged from air to Ar, whereas particles remain inside the porous glass. The remaining portion of the sample was vacuumed from the impactor at $0.75 \mathrm{~L} \mathrm{~min}^{-1}$ by means of a diaphragm pump (FTP-10B, KNF, Tokyo, Japan) equipped with a mass flow controller (MPC0005, Azbil Co., Tokyo, Japan), and ablated particles from this portion of the sample were collected on a cellulose nitrate filter (VSWP04700; pore size, $0.025 \mu \mathrm{m}$; Millipore, Tokyo, Japan) over the course of $1 \mathrm{~h}$.

Ablated particles that had passed through the GED were introduced into an infrared lamp heating device by means of a micro diaphragm gas-sampling pump (NMP05L, KNF Neuberger AG, Balterswil, Switzerland). The center of the heating device was a cylindrical glass chamber with a volume of about $190 \mathrm{~cm}^{3}$ (diameter, $20 \mathrm{~mm}$; length, $600 \mathrm{~mm}$ ), which was designed to mix ablated particles thoroughly with ultrapure water vapor or $\mathrm{HCl}$ gas. The diameters of the sample inlets and outlet of a T-shaped joint were $6 \mathrm{~mm}$. The T-shaped inlets consisted of one line for introducing the ablated particles, which came from the LA system through the impactor, and another line for ultrapure water vapor or $\mathrm{HCl}$ gas from a mantle heater. The T-shaped outlet was connected to the infrared lamp heating
Table 1 Operating conditions used for LA-ICPMS system

\begin{tabular}{|c|c|}
\hline ICPMS model & Agilent $7500 \mathrm{ce}$ \\
\hline RF power & $1600 \mathrm{~W}$ \\
\hline Ar carrier gas flow rate & $1.05 \mathrm{~L} \mathrm{~min}^{-1}$ \\
\hline Make-up Ar gas flow rate & $0.45 \mathrm{~L} \mathrm{~min}^{-1}$ \\
\hline Sweep Ar gas flow rate & $0.60 \mathrm{~L} \mathrm{~min}^{-1}$ \\
\hline Ar auxiliary gas flow rate & $1.0 \mathrm{~L} \mathrm{~min}^{-1}$ \\
\hline Ar plasma gas flow rate & $15.0 \mathrm{~L} \mathrm{~min}^{-1}$ \\
\hline $\begin{array}{l}\text { He gas flow rate in a } \\
\text { collision-reaction cell }\end{array}$ & $3.0 \mathrm{~mL} \mathrm{~min}^{-1}$ \\
\hline Isotopes measured & $\begin{array}{l}{ }^{47} \mathrm{Ti},{ }^{55} \mathrm{Mn},{ }^{59} \mathrm{Co},{ }^{63} \mathrm{Cu},{ }^{75} \mathrm{As},{ }^{88} \mathrm{Sr},{ }^{90} \mathrm{Zr} \text {, } \\
{ }^{103} \mathrm{Mo},{ }^{108} \mathrm{Sn},{ }^{121} \mathrm{Sb},{ }^{137} \mathrm{Ba},{ }^{205} \mathrm{Tl},{ }^{208} \mathrm{~Pb} \\
{ }^{232} \mathrm{Th},{ }^{238} \mathrm{U}\end{array}$ \\
\hline LA model & UP213 \\
\hline Laser type & Nd:YAG \\
\hline Wavelength & $213 \mathrm{~nm}$ \\
\hline Spot size & $100 \mu \mathrm{m}$ \\
\hline Scan speed & $5 \mu \mathrm{m} \mathrm{s}^{-1}$ \\
\hline Fluence & $2.94-5.55 \mathrm{~J} \mathrm{~cm}^{-2}$ \\
\hline Ablation mode & Line-scan mode \\
\hline Repetition rate & $20 \mathrm{~Hz}$ \\
\hline Carrier gas & Air \\
\hline Carrier gas flow rate & $1.0 \mathrm{~L} \mathrm{~min}^{-1}$ \\
\hline
\end{tabular}

device. Three infrared lamps (Heraeus, Hanau, Germany) placed at the outside of the cylindrical glass chamber were controlled by means of a variable transformer (N-130-10, Yamabishi Electric Co., Osaka, Japan). To provide a tight connection between the cylindrical glass chamber and the three lamps, a shield case was designed.

To generate ultrapure water vapor or $\mathrm{HCl}$ gas, we used the mantle heater combined with a flask. An ultrapure water or $\mathrm{HCl}$ solution was sprayed into the flask by means of a microflow nebulizer (PFA-50, ESI, Omaha, NE, USA) at a carrier gas flow rate of $0.15 \mathrm{~L} \mathrm{~min}^{-1}$ and a solution flow rate of $50 \mu \mathrm{L} \mathrm{min}{ }^{-1}$. Vapor introduced into the flask was heated at $200^{\circ} \mathrm{C}$, and then the resulting vapor or gas was introduced into the infrared lamp heating device. The air sample or ablated particles and the ultrapure water vapor or $\mathrm{HCl}$ gas were merged in the infrared 
lamp heating device, and the resulting mixtures were directly introduced into the ICPMS instrument (7500ce, Agilent Technologies, Tokyo, Japan). Heat-resistant Tygon ${ }^{\circledR}$ tubing was used for the pathways through which water vapor and $\mathrm{HCl}$ gas flowed. The pathways were covered with a ribbon heater (JK-1, AS ONE Co., Osaka, Japan) kept at $80^{\circ} \mathrm{C}$ by means of a variable transformer (N-130-10, Yamabishi Electric Co.). The pathways are indicated by shaded lines in Fig. 1. The operating conditions for the LA-ICPMS system are summarized in Table 1.

\section{Reagents}

NIST SRM 610 (National Institute of Standards and Technology, Gaithersburg, MD, USA), a glass standard material, was used as a sample. The major forms of the elements in this standard are oxides. ${ }^{14}$

A custom multielement standard solution containing $\mathrm{Be}, \mathrm{Al}, \mathrm{V}$, Cr, Mn, Co, Ni, Cu, Zn, As, Se, Mo, Ag, Cd, Sb, Ba, Tl, Pb, Th, and U (XSTC-384, SPEX CertiPrep Inc., NJ and Ti, Sn, Zr, and Sr standard solutions (1000 ppm, Kanto Chemical Co., Tokyo, Japan) were used as external standards. A Rh standard solution (1000 ppm, Kanto) was used as an internal standard.

Nitric acid (70\%, electronic laboratory grade, Kanto), HF (50\%, semiconductor grade, Daikin Industries Co., Tokyo, Japan), and $\mathrm{H}_{2} \mathrm{O}_{2}$ (30\%, electronic laboratory grade, Kanto) were used for sample digestion. Diluted $\mathrm{HCl}$ (30\%, Ultrapure grade, Tama Chemicals Co., Kanagawa, Japan) was used to change the chemical forms of the elements in the ablated particles. Ultrapure water ( $>18.2 \mathrm{M} \Omega \mathrm{cm}$, Milli-Q system, Millipore, Tokyo, Japan) was used to prepare all solutions in this work.

For the sample of X-ray photoelectron spectroscopy (XPS), the NIST SRM 610 glass was ground by an agate mortar, and $t-\mathrm{BuMe}_{2} \mathrm{SiCl}$, which was used for a standard of XPS, was laboratory synthesized.

\section{Calibration}

A custom multielement standard solution was introduced to the ICPMS via an ultrasonic nebulizer coupled with a desolvation system (U6000AT+, CETAC, Omaha, NE) for quantitative analysis (Fig. 1). The sample-introduction efficiency of the nebulizer was constant regardless of the elements, as confirmed in our previous study. ${ }^{8}$ To calculate the sample-introduction efficiency of the ultrasonic nebulizer, we introduced a $\mathrm{Cr}$ carbonyl complex standard gas into the ICPMS by means of a metal standard gas generator (J-Science Lab Co.) at a Ar flow rate of $0.05 \mathrm{~L} \mathrm{~min}^{-1}$. The sample-introduction efficiency of the ultrasonic nebulizer was calculated before each experiment, and was determined to be $2-3 \%$.

\section{Optimization of the infrared lamp heating device}

The following experiments were carried out to optimize the infrared lamp heating device. First, ablated particles were merged into the infrared lamp heating device along with either ultrapure water vapor or $\mathrm{HCl}$ gas generated from 2, 4, and $6 \mathrm{~mol} \mathrm{~L}^{-1} \mathrm{HCl}$ solutions, and introduced via the mantle heater/ flask combination, and the relative intensities of the measured elements in the various merged solutions were compared. In these experiments, the temperature of the infrared lamp heating device was fixed at $200^{\circ} \mathrm{C}$. Second, the relative intensities of the measured elements were compared at temperatures of 200 , 300 , and $400^{\circ} \mathrm{C}$ at an $\mathrm{HCl}$ concentration of $2 \mathrm{~mol} \mathrm{~L}^{-1}$.

\section{SEM and XPS observation}

The surface of ablated particles, which had been passed through the infrared lamp heating device and collected on a carbon tape, was analyzed by means of two surfacecharacterization techniques: SEM (S-4300, Hitachi HighTechnologies, Tokyo, Japan) and XPS (AXIS-His 165, Kratos/ Shimadzu Co., Kyoto, Japan). Prior to a SEM observation, the surface of the carbon tape was coated with a Pt/Pd alloy by ion sputtering (E-1045, Hitachi High-Technologies). For analysis of the XPS spectrum, Igor software (Ver. 5.0.30, WaveMetrics, Inc., OR, USA) was used.

Calculation of recoveries by comparing direct-monitoring data and filter-collection data

Ablated particles, that were collected on a cellulose nitrate filter (pore size, $0.025 \mu \mathrm{m}$ ) during ICP-MS measurements, were acid-digested as described in the literature. ${ }^{4}$ The recovery $(R)$ was calculated by the following equation:

$$
R=C_{\mathrm{d}} / C_{\mathrm{f}} \times 100, \%
$$

where $C_{\mathrm{d}}$ is the element concentration $\left(\mathrm{ng} \mathrm{\textrm {L } ^ { - 1 } )}\right.$ in ablated particles directly monitored by ICPMS after introduction via the infrared lamp heating device, and $C_{\mathrm{f}}$ is the element concentration $\left(\mathrm{ng} \mathrm{L}^{-1}\right)$ in filter-collected particles after acid digestion.

In the case of real-time monitoring, ablated particles were directly introduced into the ICP, and ions were measured. In contrast, the elements in the filter-collected particles were measured by ICPMS after acid digestion. 50\% HF ( $3 \mathrm{~mL}), 70 \%$ $\mathrm{HNO}_{3}(6 \mathrm{~mL})$, and $30 \% \mathrm{H}_{2} \mathrm{O}_{2}(1 \mathrm{~mL})$ were added to the samples, which were then digested with a microwave digestion system (MLS 1200, Milestone, Italy). After microwave digestion, HF was evaporated by means of a hot plate $\left(230^{\circ} \mathrm{C}\right)$. After the solution was reduced to $c a$. $1.0 \mathrm{~mL}$, it was diluted to $10 \mathrm{~mL}$ with ultrapure water. Therefore, the elements in the aciddigested particles on the filter were completely ionized in the ICP. Ablated particles, that had been reacted with $\mathrm{HCl}$ gas in the infrared lamp heating device, were collected on a filter and digested by the same procedures described above; it was confirmed that there was no loss of ablated particles in the infrared-lamp heating device. Therefore, the vaporization, atomization, and ionization efficiencies of directly introduced ablated particles in the ICP can be evaluated by Eq. (1).

\section{Results and Discussion}

Dependence of element increase or decrease ratios on $\mathrm{HCl}$ concentration

The melting and boiling points of oxides and chlorides of the elements studied in this work are listed in Table $2 .{ }^{15}$ The elements of the NIST SRM 610 glass are present as oxides. We assumed that chlorides were produced by reactions of the ablated particles with the $\mathrm{HCl}$ gas.

Ablated particles were merged with ultrapure water vapor or with $\mathrm{HCl}$ gas generated from 2, 4, or $6 \mathrm{~mol} \mathrm{~L}^{-1} \mathrm{HCl}$ in the infrared lamp heating device at $200^{\circ} \mathrm{C}$. For each element, an increase or decrease ratio was calculated by dividing the signal intensity obtained for ablated particles merged with $\mathrm{HCl}$ gas by the signal intensity obtained for ablated particles merged with ultrapure water vapor, and then multiplying the resulting value by $100 \%$ (Table 3 ). The highest ratios were observed when $2 \mathrm{~mol} \mathrm{~L}^{-1} \mathrm{HCl}$ was merged with the ablated particles; under these conditions, the average increase ratio was $132 \%$, whereas the average ratios when particles were merged with 4 and $6 \mathrm{~mol} \mathrm{~L}{ }^{-1} \mathrm{HCl}$ were 114 and $104 \%$, respectively. We suggest that the lower ratios observed when the ablated particles were merged with 4 and $6 \mathrm{~mol} \mathrm{~L}^{-1} \mathrm{HCl}$ were caused by loading 
Table 2 Melting and boiling points of oxides and chlorides of elements in NIST SRM 610

\begin{tabular}{|c|c|c|c|c|c|c|}
\hline \multirow{2}{*}{ Element - } & \multicolumn{3}{|c|}{ Oxide } & \multicolumn{3}{|c|}{ Chloride } \\
\hline & Formula & m.p. $/{ }^{\circ} \mathrm{C}$ & b.p. $/{ }^{\circ} \mathrm{C}$ & Formula & m.p. $/{ }^{\circ} \mathrm{C}$ & b.p. $/{ }^{\circ} \mathrm{C}$ \\
\hline As & $\mathrm{As}_{2} \mathrm{O}_{3}$ & 274 & 460 & $\mathrm{AsCl}_{3}$ & -16 & 130 \\
\hline $\mathrm{Tl}$ & $\mathrm{Tl}_{2} \mathrm{O}$ & 579 & 1080 & $\mathrm{TlCl}$ & 430 & 720 \\
\hline $\mathrm{Sb}$ & $\mathrm{Sb}_{2} \mathrm{O}_{3}$ & 655 & 1425 & $\mathrm{SbCl}_{3}$ & 73 & 220 \\
\hline Mo & $\mathrm{MoO}_{3}$ & 801 & 1155 & $\mathrm{MoCl}_{2}$ & $530^{\mathrm{a}}$ & - \\
\hline $\mathrm{Pb}$ & $\mathrm{PbO}$ & 897 & - & $\mathrm{PbCl}_{2}$ & 501 & 951 \\
\hline $\mathrm{U}$ & $\mathrm{U}_{3} \mathrm{O}_{8}$ & $1300^{\mathrm{a}}$ & - & $\mathrm{UCl}_{4}$ & 590 & 791 \\
\hline $\mathrm{Cu}$ & $\mathrm{CuO}$ & 1446 & - & $\mathrm{CuCl}_{2}$ & $630^{\mathrm{a}}$ & - \\
\hline $\mathrm{Sn}$ & $\mathrm{SnO}_{2}$ & 1630 & - & $\mathrm{SnCl}_{2}$ & 247 & 623 \\
\hline Co & $\mathrm{CoO}$ & 1830 & - & $\mathrm{CoCl}_{2}$ & 740 & 1049 \\
\hline Mn & $\mathrm{MnO}$ & 1839 & - & $\mathrm{MnCl}_{2}$ & 650 & 1190 \\
\hline $\mathrm{Ti}$ & $\mathrm{TiO}_{2}$ & 1843 & 2900 & $\mathrm{TiCl}_{2}$ & 1035 & 1500 \\
\hline $\mathrm{Ba}$ & $\mathrm{BaO}$ & 1972 & - & $\mathrm{BaCl}_{2}$ & 962 & 1560 \\
\hline $\mathrm{Sr}$ & $\mathrm{SrO}$ & 2531 & - & $\mathrm{SrCl}_{2}$ & 874 & 1250 \\
\hline $\mathrm{Zr}$ & $\mathrm{ZrO}_{2}$ & 2709 & 4300 & $\mathrm{ZrCl}_{2}$ & $772^{\mathrm{a}}$ & - \\
\hline Th & $\mathrm{ThO}_{2}$ & 3390 & 4400 & $\mathrm{ThCl}_{4}$ & 770 & 921 \\
\hline
\end{tabular}

a. Decompose.

Table 3 Effect of $\mathrm{HCl}$ concentration on the increase or decrease ratios at the heating device temperature of $200^{\circ} \mathrm{C}($ mean $\pm \mathrm{SD}, n=3)$

\begin{tabular}{lccc}
\hline & \multicolumn{3}{c}{ Ratio, $\%$} \\
\cline { 2 - 4 } Element & $2 \mathrm{~mol} \mathrm{~L}{ }^{-1} \mathrm{HCl}$ & $4 \mathrm{~mol} \mathrm{~L}^{-1} \mathrm{HCl}$ & $6 \mathrm{~mol} \mathrm{~L}^{-1} \mathrm{HCl}$ \\
\hline $\mathrm{As}$ & $123 \pm 27$ & $123 \pm 5$ & $147 \pm 21$ \\
$\mathrm{Tl}$ & $118 \pm 12$ & $110 \pm 11$ & $92 \pm 7$ \\
$\mathrm{Sb}$ & $128 \pm 18$ & $88 \pm 6$ & $87 \pm 3$ \\
$\mathrm{Mo}$ & $254 \pm 45$ & $141 \pm 35$ & $124 \pm 27$ \\
$\mathrm{~Pb}$ & $117 \pm 22$ & $112 \pm 11$ & $98 \pm 10$ \\
$\mathrm{U}$ & $109 \pm 17$ & $103 \pm 10$ & $85 \pm 7$ \\
$\mathrm{Cu}$ & $124 \pm 21$ & $125 \pm 6$ & $117 \pm 9$ \\
$\mathrm{Sn}$ & $168 \pm 28$ & $109 \pm 8$ & $106 \pm 4$ \\
$\mathrm{Co}$ & $129 \pm 12$ & $129 \pm 15$ & $125 \pm 8$ \\
$\mathrm{Mn}$ & $114 \pm 15$ & $108 \pm 6$ & $101 \pm 12$ \\
$\mathrm{Ti}$ & $125 \pm 12$ & $122 \pm 20$ & $99 \pm 8$ \\
$\mathrm{Ba}$ & $121 \pm 10$ & $110 \pm 13$ & $97 \pm 3$ \\
$\mathrm{Sr}$ & $124 \pm 16$ & $111 \pm 9$ & $100 \pm 10$ \\
$\mathrm{Zr}$ & $117 \pm 15$ & $114 \pm 9$ & $100 \pm 8$ \\
$\mathrm{Th}$ & $113 \pm 12$ & $99 \pm 15$ & $84 \pm 3$ \\
Average & 132 & 114 & 104 \\
\hline
\end{tabular}

effects. ${ }^{16}$ That is, when a large amount of $\mathrm{HCl}$ gas was introduced into the ICP, the energy of the plasma was consumed by vaporization, atomization, and ionization of the $\mathrm{HCl}$ gas, and thus the vaporization, atomization, and ionization of the elements was incomplete. Note that arsenic (As) was the only element for which the increase ratio increased with increasing $\mathrm{HCl}$ concentration; the ratio was $147 \%$ when $6 \mathrm{~mol} \mathrm{~L}^{-1} \mathrm{HCl}$ was introduced. This result was due to interference by ${ }^{40} \mathrm{Ar}^{35} \mathrm{Cl}$.

When ablated particles were merged with $2 \mathrm{~mol} \mathrm{~L}^{-1} \mathrm{HCl}$, the increase ratios were almost the same for all the measured elements, except for Mo. That is, the element-dependence of the effect of $\mathrm{HCl}$ on vaporization, atomization, and ionization was low. Our results indicated that the optimum $\mathrm{HCl}$ concentration was $2 \mathrm{~mol} \mathrm{~L}^{-1}$; this concentration was used in subsequent experiments to assess the effect of the heating device temperature on the increase ratios.
Table 4 Effect of the heating device temperature on the increase or decrease ratios at an $\mathrm{HCl}$ concentration of $2 \mathrm{~mol} \mathrm{~L}^{-1}$ (mean \pm $\mathrm{SD}, n=3$ )

\begin{tabular}{lcc}
\hline & \multicolumn{2}{c}{ Ratio, $\%$} \\
\cline { 2 - 3 } Element & $300^{\circ} \mathrm{C}$ & $400^{\circ} \mathrm{C}$ \\
\hline $\mathrm{As}$ & $89 \pm 8$ & $159 \pm 113$ \\
$\mathrm{Tl}$ & $115 \pm 6$ & $160 \pm 19$ \\
$\mathrm{Sb}$ & $136 \pm 9$ & $171 \pm 63$ \\
$\mathrm{Mo}$ & $105 \pm 7$ & $90 \pm 25$ \\
$\mathrm{~Pb}$ & $90 \pm 10$ & $58 \pm 10$ \\
$\mathrm{U}$ & $120 \pm 15$ & $140 \pm 10$ \\
$\mathrm{Cu}$ & $117 \pm 51$ & $128 \pm 10$ \\
$\mathrm{Sn}$ & $120 \pm 4$ & $105 \pm 9$ \\
$\mathrm{Co}$ & $113 \pm 5$ & $127 \pm 15$ \\
$\mathrm{Mn}$ & $111 \pm 6$ & $119 \pm 20$ \\
$\mathrm{Ti}$ & $111 \pm 1$ & $137 \pm 25$ \\
$\mathrm{Ba}$ & $103 \pm 6$ & $119 \pm 5$ \\
$\mathrm{Sr}$ & $112 \pm 2$ & $128 \pm 13$ \\
$\mathrm{Zr}$ & $106 \pm 2$ & $125 \pm 14$ \\
$\mathrm{Th}$ & $170 \pm 62$ & $254 \pm 70$ \\
$\mathrm{Average}$ & 115 & 135 \\
\hline
\end{tabular}

Dependence of increase or decrease ratios on the temperature of the infrared lamp heating device

Ablated particles were merged with $2 \mathrm{~mol} \mathrm{~L}^{-1} \mathrm{HCl}$ in the infrared lamp heating device at 200,300 , or $400^{\circ} \mathrm{C}$, and the increase or decrease ratios of the elements were calculated by dividing the element intensities for ablated particles merged with $2 \mathrm{~mol} \mathrm{~L}^{-1} \mathrm{HCl}$ at 300 and $400^{\circ} \mathrm{C}$ by the corresponding element intensities for particles merged with $2 \mathrm{~mol} \mathrm{~L}^{-1} \mathrm{HCl}$ at $200^{\circ} \mathrm{C}$. When ${ }^{59} \mathrm{Co},{ }^{90} \mathrm{Zr}$, and ${ }^{232} \mathrm{Th}$, which have high-melting oxides, were measured, the sampling depth was optimized for each of the three heating device temperatures. The optimum sampling depths at 200,300 , and $400^{\circ} \mathrm{C}$ were 9.4, 9.1, and $8.9 \mathrm{~mm}$, respectively; that is, optimum sampling depth decreased with increasing heating device temperature, owing to diffusion of ions in the ICP. ${ }^{17}$

For all elements, except for $\mathrm{Pb}$ and $\mathrm{Mo}$, the increase ratio increased as the heating device temperature was increased (Table 4). The average increase ratios for all the elements were 115 and $135 \%$ at 300 and $400^{\circ} \mathrm{C}$, respectively. The precisions of $\mathrm{Cu}$ and $\mathrm{Th}$ were large. Since the precisions of other elements were not so large, the reason for the large precision can be considered to be on artifact after laser ablation or inhomogeneity of the sample surface. We suggest that the increase in temperature promoted $\mathrm{HCl}$-induced conversion of portions of the oxides in the ablated particles to chlorides, corroded the ablated particles, and roughened their surfaces. The variation of the increase ratio with the heating device temperature was correlated with the oxide melting point: at $400^{\circ} \mathrm{C}$, large increase ratios were observed for elements with low-melting oxides, such as $\mathrm{As}, \mathrm{Tl}$, and $\mathrm{Sb}(159,160$, and 171\%, respectively). We suggest that in the infrared lamp heating device, the extent of melting, atomization, and vaporization of $\mathrm{As}, \mathrm{Tl}$, and $\mathrm{Sb}$ oxides, which have low melting points and relatively small differences between the oxide and chloride melting points, was higher than that of the high-melting oxides. Therefore, the increase ratios of these low-melting oxides were increased by the heat from the infrared lamp heating device. The increase ratios of $\mathrm{U}, \mathrm{Cu}, \mathrm{Co}, \mathrm{Mn}, \mathrm{Ti}, \mathrm{Ba}, \mathrm{Sr}$, and $\mathrm{Zr}$, which have highmelting oxides (from 1300 to $2709^{\circ} \mathrm{C}$ ), increased only slightly as the heating device temperature was increased. That is, 

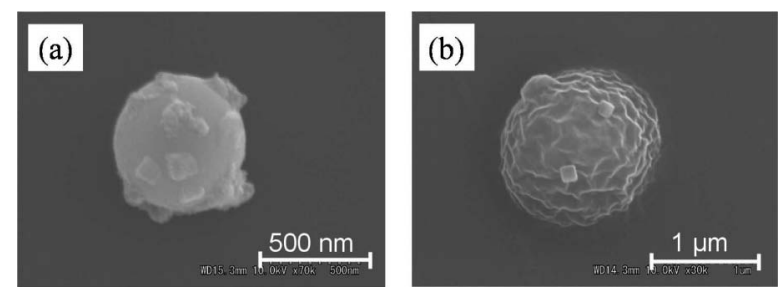

Fig. 2 SEM images of ablated particles (a) merged with ultrapure water and (b) merged with $2 \mathrm{~mol} \mathrm{~L}^{-1} \mathrm{HCl}$ at the heating device temperature of $400^{\circ} \mathrm{C}$.

the temperature dependence of the ratios for these elements was low. We suggest that the effects of corrosion and the change in the chemical form of the surface constituents by reactions with $\mathrm{HCl}$ gas were comparable for these elements, and that their vaporization, atomization, and ionization in the plasma were promoted by the increase in the heating device temperature.

In contrast, the increase ratio of thorium (Th) was markedly influenced by the heating device temperature; the ratios for Th at 300 and $400^{\circ} \mathrm{C}$ were 170 and $254 \%$, respectively. The melting points of $\mathrm{Th}$ oxide and $\mathrm{Th}$ chloride are 3390 and $770^{\circ} \mathrm{C}$, respectively, and the difference between the oxide and chloride melting points is higher for this element than for any of the other measured elements. The change from Th oxide to Th chloride on the particle surface was clearly enhanced by increasing the heating device temperature. The effect of the change in the chemical constituent on the vaporization of ablated particles in the ICP was stronger for Th oxide than for oxides with lower melting points. The ratio for $\mathrm{Pb}$ decreased to $58 \%$ at the heating device temperature of $400^{\circ} \mathrm{C}$. Since the ratio for $\mathrm{Pb}$ was improved by using a smaller sampling depth, the reason for this decrease ratio might be caused by the diffusion of ions in front of the sampling cone. In experiments involving the three different temperatures, we achieved the desired acceleration in the vaporization, atomization, and ionization at $400^{\circ} \mathrm{C}$. Therefore, we decided that the optimum heating device temperature was $400^{\circ} \mathrm{C}$.

SEM observation of ablated particles merged with $\mathrm{HCl}$ gas

Figure 2 shows SEM images of ablated particles after they were merged with ultrapure water (Fig. 2a) and $2 \mathrm{~mol} \mathrm{~L}^{-1} \mathrm{HCl}$ (Fig. 2b) in the infrared lamp heating device at $400^{\circ} \mathrm{C}$. The surface of the particles merged with water vapor was smooth, whereas the surface of the particles merged with $\mathrm{HCl}$ gas was rough. The surface was corroded by $2 \mathrm{~mol} \mathrm{~L}^{-1} \mathrm{HCl}$, the surface area of the particles increased, and the surface became friable. As a result, particles merged with $2 \mathrm{~mol} \mathrm{~L}^{-1} \mathrm{HCl}$ received more energy from the ICP than those merged with ultrapure water, and vaporization, atomization, and ionization of the particles merged with $\mathrm{HCl}$ gas were accelerated in the ICP. As shown in Table 3, the increase in the increase ratio was not element dependent when ablated particles were merged with ultrapure water or with $2 \mathrm{~mol} \mathrm{~L}^{-1} \mathrm{HCl}$ at a heating device temperature of $200^{\circ} \mathrm{C}$. Surface corrosion was a major reason for the increase in the increase ratios at the heating device temperature of $200^{\circ} \mathrm{C}$.

XPS observation of ablated particles merged with ultrapure water vapor or $\mathrm{HCl}$ gas

Ablated particles were collected on three different carbon tapes after merging with ultrapure water and $2 \mathrm{~mol} \mathrm{~L}^{-1} \mathrm{HCl}$ in the infrared lamp heating device at $400^{\circ} \mathrm{C}$, and XPS spectra were measured $(n=3)$. Since similar results were obtained,
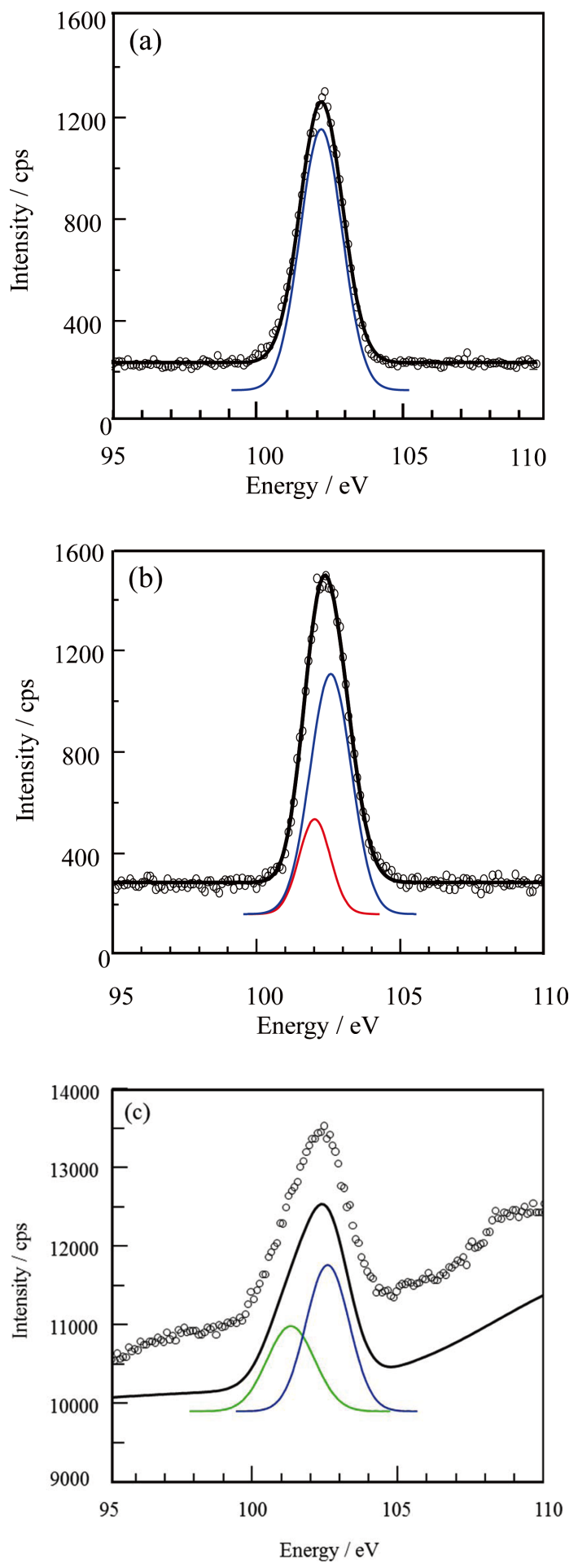

Fig. 3 Silicon 2p XPS spectra. (a) Ablated particles merged with ultrapure water at the heating device temperature of $400^{\circ} \mathrm{C}$ : XPS spectrum (open circles), peak fit (black line), and $\mathrm{SiO}_{2}$ (blue line). (b) Ablated particles merged with $2 \mathrm{~mol} \mathrm{~L}^{-1} \mathrm{HCl}$ at the heating device temperature of $400^{\circ} \mathrm{C}$ : XPS spectrum (open circles), peak fit (black line), $\mathrm{SiO}_{2}\left(\mathrm{SiO}_{2}+\mathrm{Na}_{2} \mathrm{O}\right.$, blue line), $\mathrm{SiCl}_{2}\left(\mathrm{SiO}_{2}+\mathrm{Na}_{2} \mathrm{O}\right.$, red line). (c) Mixture (1:1) of NIST SRM 610 powder and $97 \% t$-BuMe ${ }_{2} \mathrm{SiCl}$ : XPS spectrum (open circles), peak fit (black line), $\mathrm{SiO}_{2}\left(\mathrm{SiO}_{2}+\mathrm{Na}_{2} \mathrm{O}+\right.$ $t-\mathrm{BuMe}_{2} \mathrm{SiCl}$, blue line $), \mathrm{SiCl}_{2}\left(\mathrm{SiO}_{2}+\mathrm{Na}_{2} \mathrm{O}+t-\mathrm{BuMe}{ }_{2} \mathrm{SiCl}\right.$, green line).

one result is shown in this paper. Figure 3a shows the Si 2p XPS spectrum of ablated particles collected on a carbon tape after 
merging with ultrapure water. When the peak indicated by the black line was mathematically separated by means of Igor software, the single peak (peak top, $102.7 \mathrm{eV}$ ) indicated by the blue line was obtained. The NIST XPS database ${ }^{18}$ indicates that the $\mathrm{SiO}_{2}$ peak occurs between 103.0 and $104.0 \mathrm{eV}$, but the $\mathrm{SiO}_{2}$ peak observed in this study was shifted to lower energy. The $\mathrm{SiO}_{2}$ peak is shifted to low energy when glass consisting of a mixture of $\mathrm{SiO}_{2}$ and $\mathrm{Na}_{2} \mathrm{O}$ is measured by XPS, and the energy of the $\mathrm{SiO}_{2}$ peak is $0.8 \mathrm{eV}$ lower than that of the $\mathrm{SiO}_{2}$ crystal when the proportions of $\mathrm{SiO}_{2}$ and $\mathrm{Na}_{2} \mathrm{O}$ are 69 and $31 \%$, respectively. ${ }^{19}$ The position of the peak shown by the blue line in Fig. 3a was in a good agreement with the XPS peak for a mixture of $\mathrm{SiO}_{2}$ and $\mathrm{Na}_{2} \mathrm{O}$. Therefore, we assigned the peak at $102.7 \mathrm{eV}$ to $\mathrm{SiO}_{2}$.

Figure $3 b$ shows the Si $2 p$ XPS spectrum of ablated particles collected on a carbon tape after merging with $2 \mathrm{~mol} \mathrm{~L}^{-1} \mathrm{HCl}$. The red and blue lines were obtained by the peak separation of the XPS spectrum, indicated by the black line. The peak indicated by the blue line was assigned to $\mathrm{SiO}_{2}$. The top of the peak indicated by the red line was $-1.0 \mathrm{eV}$ from the top of the peak indicated by the blue line. The energy difference between the XPS peak of $\mathrm{SiO}_{2}$ with $\mathrm{Na}_{2} \mathrm{O}$ and the peak of $\mathrm{SiCl}_{2}$ is $1.0 \mathrm{eV}^{18}$ The energy difference of the red line was in good agreement with the energy difference of $\mathrm{SiCl}_{2}$. The chemical shift of $\mathrm{SiCl}_{2}$ was observed when ablated particles were merged with $2 \mathrm{~mol} \mathrm{~L}^{-1} \mathrm{HCl}$ at $400^{\circ} \mathrm{C}$. We assumed that the constituents of the particles were partially converted to chlorides when the particles were merged with $2 \mathrm{~mol} \mathrm{~L}^{-1} \mathrm{HCl}$ in the infrared lamp heating device at $400^{\circ} \mathrm{C}$. The area ratio of the $\mathrm{SiO}_{2}$ and $\mathrm{SiCl}_{2}$ peaks in Fig. 3b was 1/0.24.

We ground NIST SRM 610, which contains $72 \% \mathrm{SiO}_{2}$, in an agate mortar; and we mixed the resulting powder in a 1:1 weight ratio with $97 \% t-\mathrm{BuMe}_{2} \mathrm{SiCl}$ (which contains $\mathrm{Si}-\mathrm{Cl}$ bonds) and measured the XPS spectrum of the mixture (Fig. 3c). The peaks indicated by the blue and green lines were obtained by the peak separation of the spectrum shown by the black line. The peak indicated by the blue line originated from $\mathrm{SiO}_{2}$, and that indicated by the green line (peak top, $101.0 \mathrm{eV}$ ) was assigned to $\mathrm{SiCl}_{2}$. The ratio of the $\mathrm{SiO}_{2}$ and $\mathrm{SiCl}_{2}$ peak areas was $1 / 0.66$. To estimate the proportion of $\mathrm{SiO}_{2}$ that was changed to $\mathrm{SiCl}_{2}$, we calculated the $\mathrm{SiO}_{2}$ and $\mathrm{SiCl}_{2}$ ratio in particles merged with $2 \mathrm{~mol} \mathrm{~L}-1 \mathrm{HCl}$ at $400^{\circ} \mathrm{C}$ from the $\mathrm{SiO}_{2} / \mathrm{SiCl}_{2}$ peak area ratio in Fig. 3c. When the $\mathrm{SiO}_{2} / \mathrm{SiCl}_{2}$ ratio was $1: 1$, the $\mathrm{SiO}_{2} / \mathrm{SiCl}_{2}$ peak area ratio was 1/0.66 (Fig. 3c); whereas the $\mathrm{SiO}_{2} / \mathrm{SiCl}_{2}$ ratio in ablated particles merged with $\mathrm{HCl}$ gas was $1 / 0.24$ (Fig. 3b). Therefore, the $\mathrm{SiO}_{2} / \mathrm{SiCl}_{2}$ ratio when particles were merged with $2 \mathrm{~mol} \mathrm{~L}^{-1} \mathrm{HCl}$ at $400^{\circ} \mathrm{C}$ was $1 / 0.36$, where 0.36 was calculated by dividing 0.24 by 0.66 . The ratio of chlorides to the total constituents can be calculated as $0.36 /(1.00+0.36)=0.26$. This result indicates that $26 \%$ of $\mathrm{Si}$ oxides were changed to chlorides on the surface. However, the XPS spectra were measured only to a depth of about $10 \mathrm{~nm}$ on the surface of the particles, which had diameters of less than $1 \mu \mathrm{m}$. It is likely that the constituents in the core of the ablated particles were not changed.

\section{Recovery under optimum conditions}

We determined the element recovery ratios under the optimum conditions $\left(2 \mathrm{~mol} \mathrm{~L}^{-1} \mathrm{HCl}, 400^{\circ} \mathrm{C}\right)$ at a sampling depth of $8.9 \mathrm{~mm}$ (Fig. 4). The recoveries of all the elements, except for As, were higher when ablated particles were merged with $2 \mathrm{~mol} \mathrm{~L}^{-1} \mathrm{HCl}$ than when they were merged with ultrapure water. The average increase in the recovery for the measured elements was $23 \%$. The recoveries of elements with highmelting oxides increased substantially; e.g., the recoveries of $\mathrm{Sr}$, $\mathrm{Zr}$, and Th increased from 66 to $95 \%$, from 67 to $99 \%$, and from

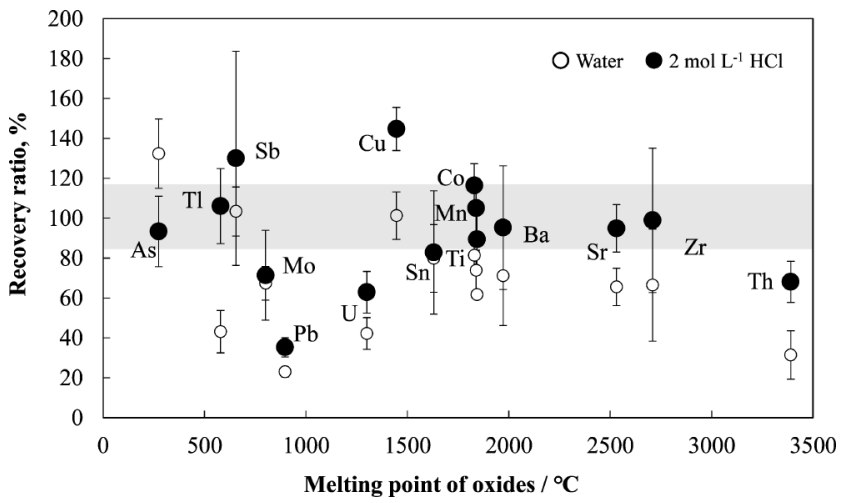

Fig. 4 Recovery ratios as a function of the oxide melting point, obtained by merging ablated particles with $2 \mathrm{~mol} \mathrm{~L}^{-1} \mathrm{HCl}$ at the heating device temperature of $400^{\circ} \mathrm{C}$ and a sampling depth of $8.9 \mathrm{~mm}$. Experiments we repeated three times $(n=3)$.

32 to $68 \%$, respectively. For high-melting oxides, vaporization, atomization, and ionization in the ICP were accelerated by merging the ablated particles with $2 \mathrm{~mol} \mathrm{~L}^{-1} \mathrm{HCl}$ in the infrared lamp heating device at $400^{\circ} \mathrm{C}$. Note that because polyatomic ${ }^{40} \mathrm{Ar}^{35} \mathrm{Cl}$ interferes with ${ }^{75} \mathrm{As}$, masses of 77 and 78 were simultaneously measured, and the recovery of ${ }^{75} \mathrm{As}$ was determined by means of the interference correction equation ${ }^{20}$ (Fig. 4 shows the recovery of As after interference correction). Ablated particles collected on a filter were microwave-digested, and then a hot plate was used for the evaporation of hydrofluoric acid. There is a possibility that volatile elements, such as As and $\mathrm{Sb}$, were not completely collected on a filter, or might have been partially vaporized during acid digestion on a hot plate. For that reason, the concentration of $\mathrm{Sb}$ in filter-collection data was low and the recovery of $\mathrm{Sb}$ became $130 \%$. The recoveries of $\mathrm{Mo}, \mathrm{Pb}$, and $\mathrm{U}$ were relatively low: 71,35 , and $63 \%$, respectively, when the particles were merged with $\mathrm{HCl}$ gas. The melting points of the oxides of $\mathrm{Mo}, \mathrm{Pb}$, and $\mathrm{U}$ are 801, 897, and $1300^{\circ} \mathrm{C}$, respectively. Because the vaporization, atomization, and ionization of these elements in the ICP were accelerated by merging of the particles with $\mathrm{HCl}$ gas in the infrared lamp heating device, the ions diffused in front of the sampling cone, which decreased the recovery of elements with low-melting oxides. In contrast, the recoveries of $\mathrm{As}, \mathrm{Tl}, \mathrm{Mn}, \mathrm{Ba}, \mathrm{Sr}$, and $\mathrm{Zr}$ were $100 \pm 10 \%$.

To eliminate the diffusion of ions of elements with lowmelting oxides, we changed the sampling depth from 8.9 to 8.4 $\mathrm{mm}$, and then determined the element recoveries under the optimized conditions (Fig. 5). Under these conditions, the recoveries of $\mathrm{Mo}, \mathrm{Pb}$, and $\mathrm{U}$ improved from 71 to $123 \%$, from 35 to $81 \%$, and from 63 to $112 \%$, respectively, when the particles were merged with $\mathrm{HCl}$ gas. This improvement likely resulted from more-efficient sampling of the ions produced from the ablated particles. However, changing the sampling depth decreased the recoveries of elements with high-melting oxides; specifically, the recoveries of $\mathrm{Mn}, \mathrm{Ti}, \mathrm{Ba}, \mathrm{Sr}, \mathrm{Zr}$, and $\mathrm{Th}$ decreased by about $45 \%$ relative to the recoveries at a sampling depth of $8.9 \mathrm{~mm}$. This change was caused by the short plasma residence time. In the ablated particles, high-melting oxides were incompletely vaporized, atomized, and ionized in the ICP, and therefore the recovery decreased. 


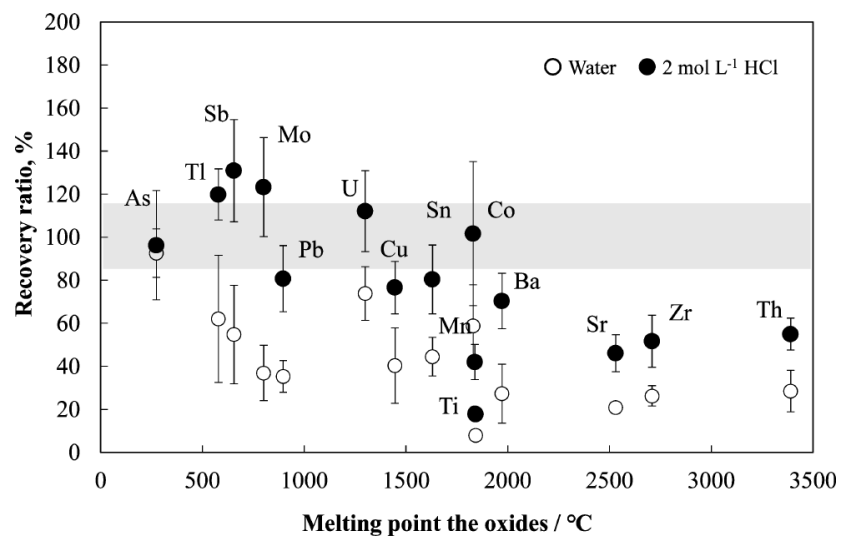

Fig. 5 Recovery ratios as a function of the oxide melting point, obtained by merging ablated particles with $2 \mathrm{~mol} \mathrm{~L}^{-1} \mathrm{HCl}$ at the heating device temperature of $400^{\circ} \mathrm{C}$ and a sampling depth of $8.4 \mathrm{~mm}$. Experiments we repeated three times $(n=3)$.

\section{Conclusions}

Merging ablated particles with $\mathrm{HCl}$ gas produced by heating an $\mathrm{HCl}$ solution resulted in an average $135 \%$ increase in the element concentrations compared with concentrations obtained when the particles were merged with ultrapure water. The increase could be explained by two factors: a change in the chemical constituents of the particles from oxides to chlorides and a change in the surface roughness and friability of the particles. XPS results indicated that $26 \%$ of Si oxides were changed to $\mathrm{Si}$ chlorides on the surface of ablated particles merged with $2 \mathrm{~mol} \mathrm{~L}^{-1} \mathrm{HCl}$ at the heating device temperature of $400^{\circ} \mathrm{C}$. The increase ratio of the elements increased as the temperature of the infrared lamp heating device was increased. On average, the increase ratio increased by $135 \%$ when the temperature of the infrared lamp heating device was increased from 200 to $400^{\circ} \mathrm{C}$. The change in the increase ratio was dependent on the oxide melting point. The increase ratios for $\mathrm{As}, \mathrm{Tl}$, and $\mathrm{Sb}$, which have relatively low-melting oxides and relatively small differences between the oxide and chloride melting points, were increased less by the increase of the infrared lamp heating device temperature than was the increase ratio for $\mathrm{Th}$, which has a high-melting oxide and a large difference in the melting point between the oxide and chloride, and which showed a remarkable increase when the heating device temperature was increased. The chemical change in the particle constituents was promoted by the increase in the heating device temperature; this promotion resulted in an increase in the increase ratio.

When ablated particles were merged with $2 \mathrm{~mol} \mathrm{~L}^{-1} \mathrm{HCl}$ at heating device temperature of $400^{\circ} \mathrm{C}$, the element recovery at a sampling depth of $8.9 \mathrm{~mm}$ increased by $23 \%$ on average relative to the recovery when ablated particles were merged with ultrapure water. The recoveries of $\mathrm{Sr}, \mathrm{Zr}$, and $\mathrm{Th}$, which have high-melting oxides, were 29,32 , and $36 \%$ higher, respectively, than the recoveries with ultrapure water. The recoveries of elements with relatively low-melting oxides, such as $\mathrm{Mo}, \mathrm{Pb}$, and $\mathrm{U}$, decreased when particles were merged with $2 \mathrm{~mol} \mathrm{~L}^{-1}$ $\mathrm{HCl}$, owing to the diffusion of ions prior to the sampling cone. Changing the sampling depth from 8.9 to $8.4 \mathrm{~mm}$ improved the recoveries of $\mathrm{Mo}, \mathrm{Pb}$, and $\mathrm{U}$ from 71 to $123 \%$, from 35 to $81 \%$, and from 63 to $112 \%$, respectively, when the particles were merged with $\mathrm{HCl}$ gas. This improvement likely resulted from more-efficient sampling of the ions produced from the ablated particles. This experimental result suggests that special attention to the diffusion of ions is necessary when elements with relatively low-melting oxides are measured.

\section{Acknowledgements}

This research was supported by the Ministry of Education, Culture, Sports, Science and Technology, Japan, through a Grant-in-Aid for Young Scientists (B) (No. 26870595) and a Grant-in-Aid for Scientific Research (C) (No. 26410160). The authors thank Mr. Kohei Nishiguchi and the late Mr. Keisuke Utani of J-Science Lab Co. for instrumental support and invaluable comments.

\section{References}

1. D. B. Aeschliman, S. J. Bajic, D. P. Baldwin, and R. S. Houk, J. Anal. At. Spectrom., 2003, 18, 1008.

2. K. S. Ho, K. O. Lui, K. H. Lee, and W. T. Chan, Spectrochim. Acta, Part B, 2013, 89, 30.

3. N. Furuta, A. Ijima, A. Kambe, K. Sakai, and K. Sato, J. Environ. Monit., 2005, 7, 1155.

4. Y. Suzuki, T. Suzuki, and N. Furuta, Anal. Sci., 2010, 26, 929.

5. Y. Suzuki, S. Hikida, and N. Furuta, J. Environ. Monit., 2011, 13, 3420.

6. T. Myojo, M. Takaya, and M. Ono-Ogasawara, Aerosol Sci. Technol., 2002, 36, 76.

7. K. Nishiguchi, K. Utani, and E. Fujimori, J. Anal. At. Spectrom., 2008, 23, 1125.

8. Y. Suzuki, H. Sato, S. Hikida, K. Nishiguchi, and N. Furuta, J. Anal. At. Spectrom., 2010, 25, 947.

9. Y. Suzuki, H. Sato, K. Hiyoshi, and N. Furuta, Spectrochim. Acta, Part B, 2012, 76, 133.

10. R. Brogioli, B. Hattendorf, J. Koch, H. Wiltsche, L. Flamigni, and D. Günther, Anal. Bioanal. Chem, 2011, 399, 2201.

11. L. Flamigni, J. Koch, H. Wiltsche, R. Brogioli, S. Gschwind, and D. Günther, J. Anal. At. Spectrom., 2012, 27, 619.

12. R. Machida, T. Nakazawa, and N. Furuta, Anal. Sci., 2015, 31,345 .

13. R. Machida, T. Nakazawa, and N. Furuta, J. Anal. At. Spectrom., 2016, 31, 809.

14. J. S. Kane, Geostand. Newslett.-J. Geostand., 1998, $22,7$.

15. D. R. Lide, "CRC Handbook of Chemistry and Physics", 2005, 86th ed., Taylor \& Francis, New York, 4 - 44.

16. I. Kroslakova and D. Günther, J. Anal. At. Spectrom., 2007, $22,51$.

17. K. O. Lui, Ph. D. Thesis, The University of Hong Kong, 2011.

18. A. V. Naumkin, A. Kraut-Vass, S. W. Gaarenstroom, and C. J. Powell, NIST Standard Reference Database 20, Ver. 4.1, http://srdata.nist.gov/xps/.

19. A. Mekki, D. Holland, C. F. McConville, and M. Salim, J. Non-cryst. Solids, 1996, 267.

20. Method 6020 Inductively Coupled Plasma-Mass Spectrometry, CLP-M Ver. 9, "Test Methods for Evaluating Solid Wastes Physical/Chemical Methods", 1994, U. S. Environmental Protection Agency, USA. 